\title{
Cetoacidosis asociada a colecistitis aguda
}

\author{
Carlos Gómez González ${ }^{\mathrm{a}}$, Laura Arriero Ollero ${ }^{\mathrm{b}}$, Manuel Romero Cruzc, Juan Carlos \\ Domínguez Herencias ${ }^{c}$
}

\author{
${ }^{a}$ M.I.R. de Medicina de Familia y \\ Comunitaria. Unidad Docente de \\ Talavera de la Reina. \\ Talavera de la Reina (Toledo). \\ España.

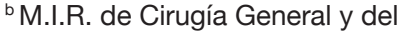 \\ Aparato Digestivo. \\ Hospital Nuestra Señora del \\ Prado. Talavera de la Reina \\ (Toledo). España. \\ ${ }^{\circ}$ D.U.E. Servicio de Urgencias. \\ Hospital Nuestra Señora del \\ Prado. Talavera de la Reina \\ (Toledo). España. \\ Correspondencia: \\ Carlos Gómez González. \\ Correo electrónico: \\ ccgg143@gmail.com.
}

Recibido el 5 de marzo de 2014. Aceptado para su publicación el 22 de abril de 2014.

\section{RESUMEN}

Varón de 62 años con diabetes mellitus tipo 1 (DM-1) en tratamiento con insulina soluble humana de acción rápida y fumador de 20-30 cigarrillos/día que acudió al Servicio de Urgencias por alteración del estado general. Refiere niveles elevados de glucemia, a pesar de haber disminuido la ingesta de alimentos, que no consigue controlar con su pauta habitual de insulina. Asocia un cuadro de deposiciones diarreicas en los últimos días, además de polidipsia. Comenta también cuadro de dolor abdominal tipo cólico, difuso, de tiempo indeterminado de evolución, que no relaciona con el cuadro actual. Con una exploración prácticamente anodina a su llegada y unas alteraciones analíticas que podrían ser secundarias a su descompensación diabética, fueron las pruebas de imagen quienes nos dieron el diagnóstico final.

Palabras Clave. Cetoacidosis Diabética. Colecistitis Aguda. Diabetes Mellitus.

\section{ABSTRACT}

\section{Ketoacidosis associated with acute cholecystitis}

A 62 year old male with type 1 Diabetes mellitus (DM-1) being treated with short acting soluble human insulin, a smoker of 20-30 cigarettes per day, and who goes to the emergency department because of a deterioration in his general state of health. He has high blood sugar levels, despite having reduced intake of food which he is unable to control with his normal dosage of insulin. There is an associated clinical picture of loose stools over the last few days, as well as polydipsia. He also mentions abdominal cramps whose time of onset is vague, and which he does not relate to the current clinical picture. With a practically anodyne examination on his arrival and test abnormalities which could have been side effects of his diabetic imbalance, it was the imaging tests which provided the final diagnosis.

Key words: Diabetic Ketoacidosis. Acute Cholecystitis, Acute. Diabetes mellitus.

\section{INTRODUCCIÓN}

La diabetes mellitus (DM) es una patología muy frecuente en las consultas de Atención Primaria, y sus descompensaciones lo son en los Servicios de Urgencias. Aunque el incumplimiento dietético es una de las causas del difícil control de los valores de glucemia, muchas otras pueden ser las que produzcan dichas alteraciones y desencadenen complicaciones graves como la cetoacidosis diabética: deficiencia o resistencia a insulina, hipersecreción de glucagón, infecciones (del 30 al $60 \%$, donde predomina la infección respiratoria, gastroenteritis aguda y la infección del tracto urinario), uso de fármacos, estrés, drogas de abuso, etcétera ${ }^{1-3}$.

La colecistitis aguda hace referencia a la inflamación de la vesícula biliar y, además de los hallazgos clínicos y radiológicos, muestra hallazgos analíticos como la leucocitosis. La hiperglucemia, aunque puede presentarse, no tiene por qué existir. No siempre se presentará infección de bilis en estos pacientes, y cuando ello sucede los agentes más frecuentes son Escherichia coli, Enterococcus, Klebsiella y Enterobacter ${ }^{4,5}$.

Para el correcto control de esta patología, la colaboración del personal de enfermería y el médico es fundamental, no solo en la consulta diaria sino tam- 
bién en los procesos de descompensación ya que, aunque "la diabetes es una enfermedad que mata silenciosamente si no se controla correctamente", también lo pueden hacer sus complicaciones.

\section{CASO CLÍNICO}

Varón de 62 años con DM tipo 1 (DM-1) en tratamiento con insulina soluble humana de acción rápida y fumador de 20-30 cigarrillos/día. El paciente presenta un aspecto desaseado. Vive solo en el campo y se considera "ermitaño", aunque tiene buena relación con vecinos del pueblo cercano.

Acude al Servicio de Urgencias Hospitalarias por alteración del estado general. Refiere niveles elevados de glucemia, a pesar de haber disminuido la ingesta de alimentos, que no consigue controlar con su pauta habitual de insulina. Asocia un cuadro de deposiciones diarreicas en los últimos días, además de polidipsia. Comenta también un cuadro de dolor abdominal tipo cólico, difuso, de tiempo indeterminado de evolución, que no relaciona con el cuadro actual.

A su llegada se encuentra estable hemodinámicamente, aunque presentaba niveles de glucemia capilar elevados (GC: HI). A la exploración llama la atención el aspecto desaseado y deteriorado del paciente, aunque conversacionalmente impresiona de alguien culto. El abdomen era blando, depresible, con dolor difuso a la palpación, Murphy y Blumberg negativos, ruidos hidroaéreos presentes, sin signos de irritación peritoneal. Se palpa dudosa masa en el hemiabdomen derecho. Se inicia tratamiento con omeprazol, paracetamol, sueroterapia e insulina en bomba.

Analíticamente el paciente presenta un hemograma con 22.400 leucocitos y 18.900 neutrófilos; la bioquímica muestra una glucosa de $555 \mathrm{mg} /$ dl, creatinina 2,11 mg/dl, urea $91 \mathrm{mg} / \mathrm{dl}, \mathrm{Na}^{+} 128$ $\mathrm{mmol} / \mathrm{l}$, PCR $334 \mathrm{mg} / \mathrm{L}$. En la gasometría arterial basal se aprecia un $\mathrm{pH}$ de 7,20. Estos hallazgos analíticos, justificados por la descompensación del paciente, comienzan a corregirse poco a poco tras la administración del tratamiento. Se realiza una radiografía $(\mathrm{Rx})$ de tórax, que es normal; y una $\mathrm{Rx}$ de abdomen (figura 1). Tras los hallazgos en la $\mathrm{Rx}$ de abdomen se comenta con el radiólogo de guardia, quien aconseja la realización de una ecografía abdominal (figura 2), apreciándose una vesícula biliar de $11 \mathrm{~cm}$ de longitud con múltiple litiasis y engrosamiento de la pared.

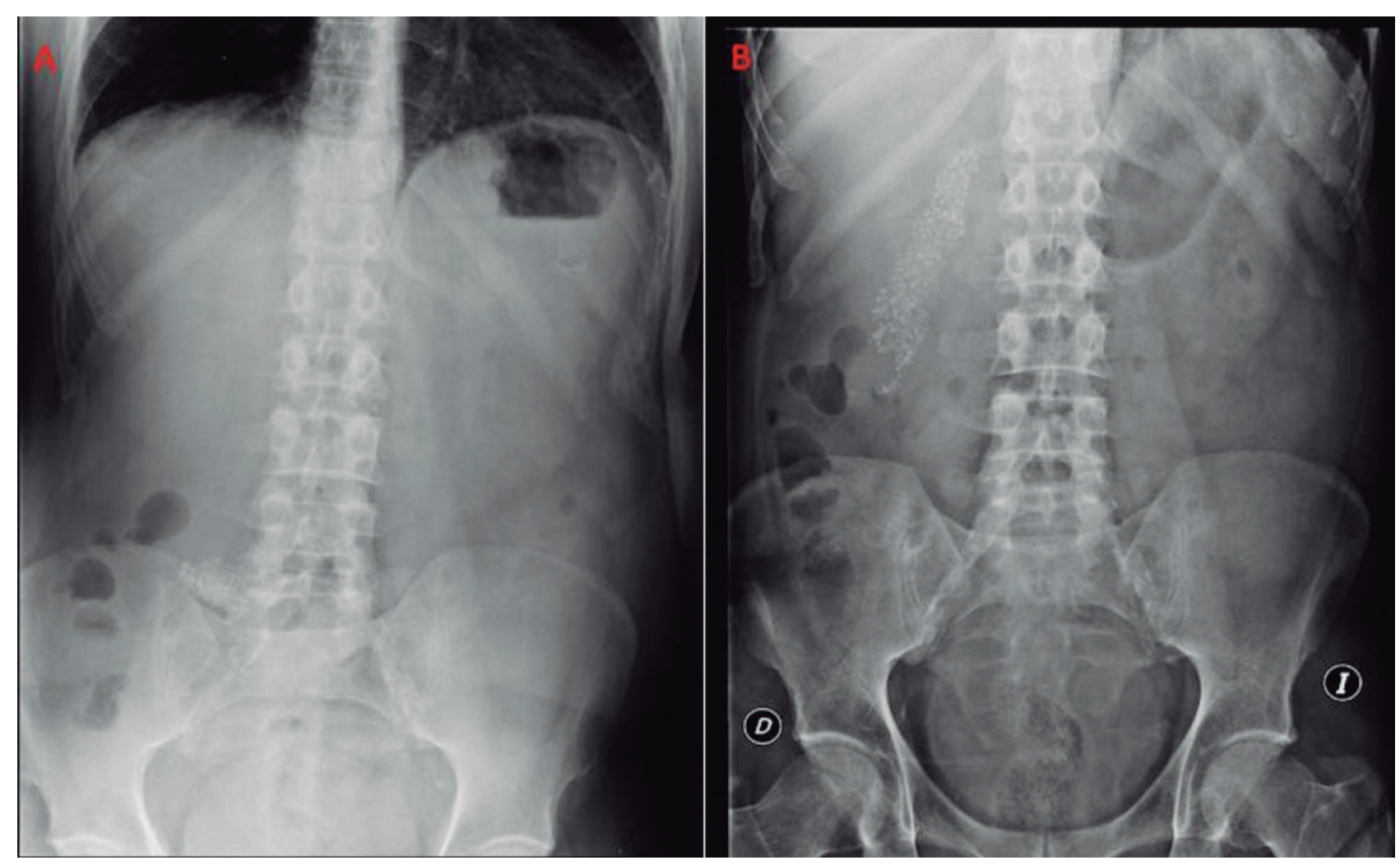

Figura 1. A: Se aprecian niveles hidroaéreos en la fosa ilíaca derecha. Imagen cálcica a la altura de la apófisis transversa derecha de la $5^{\mathrm{a}}$ vértebra lumbar. B: Se aprecian imágenes litiásicas en la región del hipocondrio derecho 

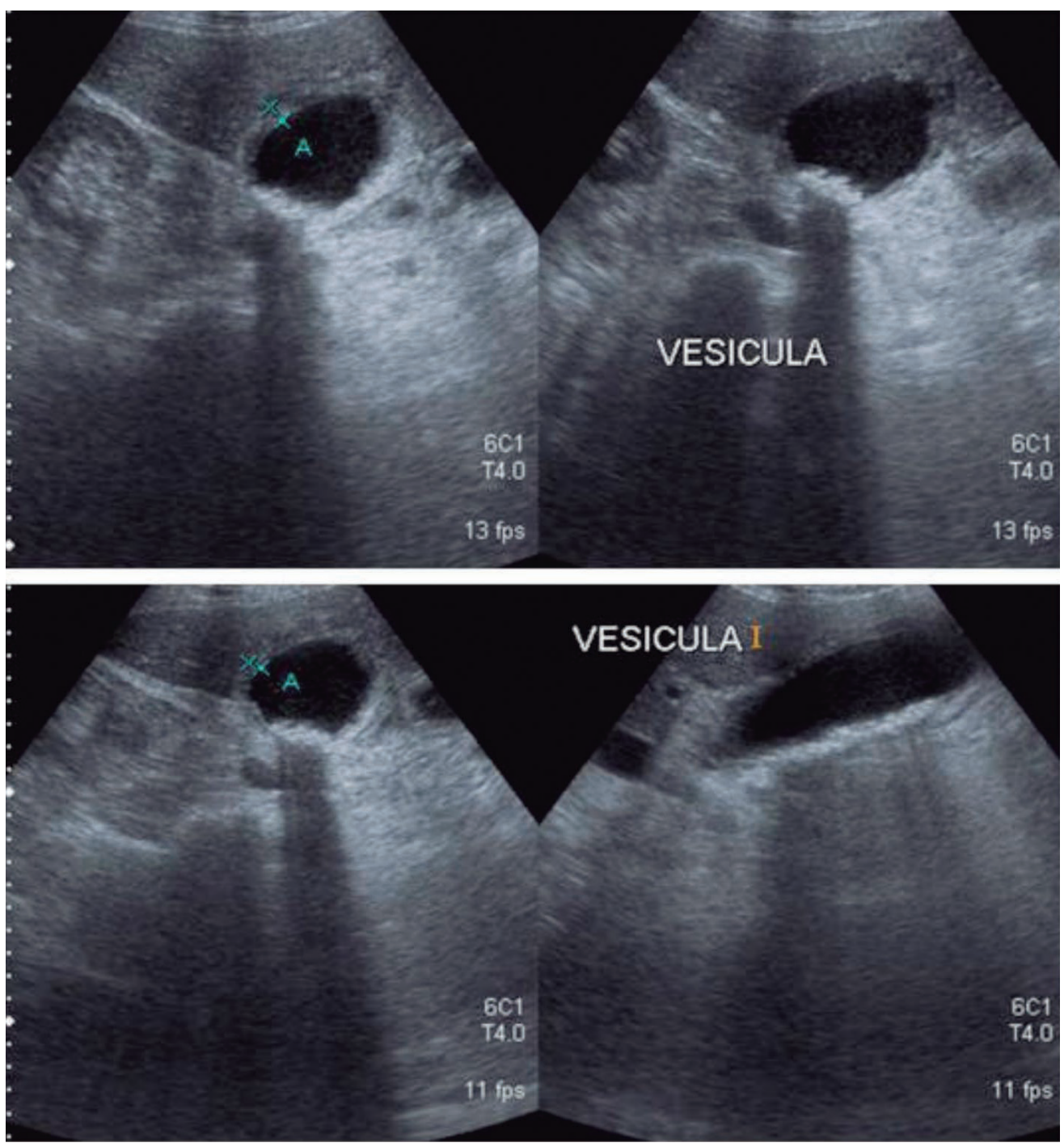

Figura 2. Vesícula biliar de $11 \mathrm{~cm}$ con dilatación de pared. Litiasis que dejan sombra acústica

Con el diagnóstico de cetoacidosis diabética secundaria a colecistitis aguda, se realiza una interconsulta con el servicio de Cirugía General, quienes deciden intervenirlo de urgencias. En un primer momento, el paciente se niega a realizarse la intervención. En ese momento, ambos residentes responsables del paciente comienzan a explicarle el riesgo de no realizar la intervención y las posibles consecuencias de la misma. Tras 90 minutos de conversación, contestando a las preguntas del paciente e intentando hacerle entender lo importante que es la intervención para la resolución del proceso, el paciente acepta la cirugía.

Tras la intervención quirúrgica el paciente es trasladado a planta de cirugía donde evoluciona favorablemente. Tras reajuste de medicación por parte de endocrinología, es dado de alta con sus valores de glucemia controlados y una pauta más actual que la que él utilizaba.

\section{DISCUSIÓN}

La mitad de los diabéticos tipo 1 presentan cetoacidosis diabética en el momento de su diagnóstico, siendo esta la primera causa de morbimortalidad por $\mathrm{DM}^{1-3}$. Se trata de una emergencia potencialmente letal si no se trata correctamente, siendo a veces susceptible de cuidados intensivos. Puede presentar una clínica variada: poliuria, polidipsia, nicturia, hiperventilación, dolor abdominal, deshidratación, etc. ${ }^{1-3}$, por lo que se debe explorar al paciente detalladamente para filiar el origen del cuadro evitando el incorrecto manejo de la patología. Unos valores de glucemia que no se modifican a pesar de la no ingesta y de continuar con la pauta de insulina habitual e incluso aumentar la misma, deben alertarnos de que algo se nos está escapando. 
En nuestro caso el foco infeccioso versus inflamatorio fue la vía biliar, que aunque no se encuentre entre los más frecuentes, produjo una importarte descompensación en la situación del paciente, por lo que se decide intervenir quirúrgicamente ${ }^{4,5}$. Además del tratamiento quirúrgico y dependiendo del grado de gravedad del paciente se ofrecen otras medidas terapéuticas como el drenaje percutáneo de la vía biliar y la colangiopancreatografía retrograda endoscópica (CPRE), técnicas que no están exentas de riesgo y tras las cuales se recomienda cirugía. Además de esto, los paciente precisan tratamiento antibiótico si el proceso lleva más de 72 horas de evolución, y un buen control del dolor y del estado hemodinámico ${ }^{4,5}$.

La relación médico-paciente en los Servicios de Urgencias es algo que habitualmente se mantiene en segundo lugar, pudiendo ser por la saturación de dichas unidades y por el poco tiempo que se dispone con los pacientes. Aun siendo esto así, este pilar fundamental en la medicina debe alcanzar una gran importancia para poder llevar a cabo los procedimientos necesarios para la salud del paciente.

\section{BIBLIOGRAFÍA}

1. Palmer C, Jessup A. Ketoacidosis in patients with type 2 diabetes. Nurse Pract. 2012; 37 (5): 13-7.

2. Kitabchi A. Epidemiology and pathogenesis of diabetic ketoacidosis and hyperosmolar hyperglycemic state. UpToDate. Literature review current through: Mar 2014 (last updated: nov 7, 2013). Disponible en: http:// www.uptodate.com.

3. García Rodríguez MJ, Antolí Royo AC, González Maroño C, García Mingo A. Complicaciones hiperglucémicas agudas de la diabetes mellitus: cetoacidosis diabética y estado hiperosmolar hiperglucémico. Medicine. 2008; 10 (18):117783.

4. Zakko S, Afdhal N. Pathogenesis, clinical features, and diagnosis cholecystitis. UpToDate. Literature review current through: Mar 2014 (last updated: sep 11, 2013). Disponible en: http:// www.uptodate.com.

5. Zakko S, Afdhal N, Vollmer C. Treatment of acute cholecystitis. UpToDate. Literature review current through: Mar 2014 (last updated: sep 25, 2012). Disponible en: http:// www.uptodate.com. 